\title{
Direct Synthesis of Radioactive Gold Nanoparticles Using a Research Nuclear Reactor
}

\author{
Maria C. Garcia Toro, Joshua P. Schlegel, and Carlos H. Castano Giraldo \\ Department of Mining and Nuclear Engineering, Missouri University of Science and Technology, Rolla, Missouri
}

\begin{abstract}
We report the single-step synthesis of radioactive gold nanoparticles with an activity and size appropriate for potential use in cancer treatment and diagnosis. Methods: A solution of $2 \mathrm{mM}$ gold chloride $\left(\mathrm{HAuCl}_{4} \cdot 3 \mathrm{H}_{2} \mathrm{O}\right), 1 \mathrm{mM}$ polyvinylpyrrolidone (molecular weight, 360,000), and $60 \mathrm{mM}$ 2-propanol was prepared in deionized water. Seven different samples of the solution were irradiated in a neutron flux of $7.45 \times 10^{12} \mathrm{n} / \mathrm{cm}^{2} \cdot \mathrm{s}$ in a research reactor for $0.5,1,3,5,10,30$, or $60 \mathrm{~min}$. The resulting nanoparticles were characterized for morphology and chemical composition using a transmission electron microscope and ImageJ. Results: The obtained nanoparticles were $3-450 \mathrm{~nm}$ in size. The average size depended on the length of irradiation, with a longer irradiation producing smaller nanoparticles. Irradiation for $10 \mathrm{~min}$ produced nanoparticles with characteristics suitable for potential cancer treatment and diagnosis (average size, $50 \mathrm{~nm}$; activity, $6.85 \mathrm{MBq} / \mathrm{mL}$ ). Conclusion: Direct production of chemically stable radioactive gold nanoparticles was successfully accomplished using the Missouri University of Science and Technology reactor. The nanoparticles had physical and radioactive characteristics potentially useful for cancer treatment and diagnosis.
\end{abstract}

Key Words: gold nanoparticles; radioactive nanoparticles; cancer nanotechnology; nanomaterials; cancer treatment and diagnosis

J Nucl Med Technol 2018; 46:280-284

DOI: $10.2967 /$ jnmt.117.206367

C ancer and heart disease are the principal causes of death around the world (1). The American Cancer Society, with the help of the National Cancer Institute, the National Program of Cancer Registries, the National Center for Health Statistics, and the North American Association of Central Cancer Registries, projected that 1,688,780 new cancer cases and 600,920 cancer deaths would occur in the United States during 2017 (2). Accordingly, billions of dollars are being invested in research to increase knowledge about the causes and biology of cancer and to develop effective therapies to improve patient outcomes. Some dis-

\footnotetext{
Received Nov. 30, 2017; revision accepted Mar. 21, 2018.

For correspondence contact: Carlos H. Castano Giraldo, Department of Mining and Nuclear Engineering, Missouri University of Science and Technology, 301 W. 14th St., Rolla, MO 65409.

E-mail: castanoc@mst.edu

Published online May 3, 2018

COPYRIGHT (c) 2018 by the Society of Nuclear Medicine and Molecular Imaging.
}

advantages of current cancer therapies include inability to bypass biologic barriers, poor delivery, inadequate distribution in the body, difficult detection by imaging (3), and radiation damage to normal tissue (4). The application of nanotechnology in cancer treatment is helping overcome these limitations, increasing the possibility of defeating the disease and extending life expectancy (5).

Gold nanoparticles have been used in cancer diagnosis and treatment because of their high stability, low reactivity, low toxicity to the human body, and easy surface-functionalization process (6-8). Gold nanoparticles have also been used to enhance imaging, and their ability to increase absorption or scattering of radiation has found applications in photothermal therapy, chemotherapy, and radiation therapy (9-12). The newest research on cancer treatment with gold nanoparticles has been on the use of ${ }^{198} \mathrm{Au}$ and ${ }^{199} \mathrm{Au}$ radioactive isotopes for locally irradiating and killing tumor cells (13). The properties of ${ }^{198} \mathrm{Au}$ and ${ }^{199} \mathrm{Au}$ (half-life, 2.695 and $3.169 \mathrm{~d} ; \beta_{\text {avg }}, 312$ and $86 \mathrm{keV} ; \beta_{\max }, 961$ and $453 \mathrm{keV}$; and $\gamma, 412$ and $159 \mathrm{keV}$, respectively) allow easy manipulation of the nanoparticles during transport and chemical processing before clinical application.

Previous research has been on the properties of radioactive gold nanoparticles for treating cancer cells in mice (1317). Nanoparticles with $\beta$-emission at energies of a few megaelectron-volts can be used to treat tumors with a maximum diameter of $1 \mathrm{~cm}(15)$. The $\beta$-emission energy of ${ }^{198} \mathrm{Au}$ $\left(\beta_{\max }, 0.96 \mathrm{MeV}\right)$ allows use of radioactive gold nanoparticles as a permanent implant in brachytherapy, where it is possible to kill cancer cells using doses higher than $50 \mathrm{~Gy}(13,15)$. One of the studies found that the overall tumor volume could be reduced by $82 \%$ after $3 \mathrm{wk}$ of treatment using an intratumoral administration of radioactive gold nanoparticles with an activity of $15.1 \mathrm{MBq}$ (13). Some studies have also demonstrated the possibility of treating tumors by using $\mathrm{x}$-ray beam irradiation of inert gold nanoparticles rather than activated gold nanoparticles $(18,19)$. The principal advantage of using radioactive gold nanoparticles is a reduction in the duration, dosage, and side effects of chemotherapy.

Many studies have been published on different methods to produce radioactive gold nanoparticles $(14,19-23)$. Most of these methods require two steps: synthesis of the nanoparticles by chemical, physical, or biologic process, followed by activation of the nanoparticles using a neutron 


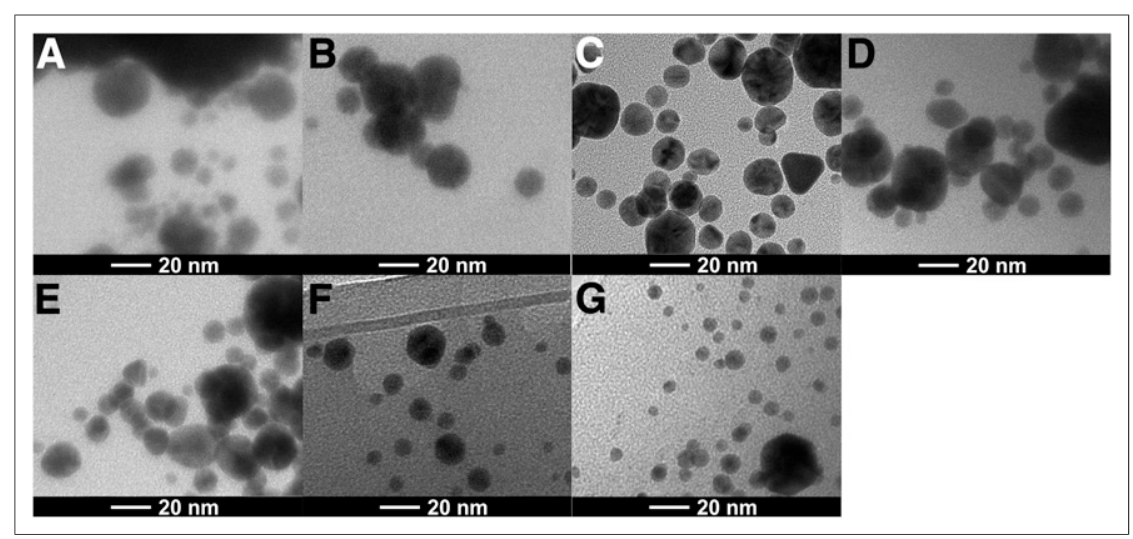

FIGURE 1. Transmission electron micrographs of radioactive gold nanoparticles that were irradiated at $200 \mathrm{~kW}$ for $0.5 \mathrm{~min}$ for sample 1 (A), 1 min for sample 2 (B), 3 min for sample $3(C), 5 \mathrm{~min}$ for sample $4(\mathrm{D}), 10 \mathrm{~min}$ for sample $5(E), 30 \mathrm{~min}$ for sample $6(E)$, and 60 min for sample $7(G)$.

source. This article describes a novel method to produce radioactive gold nanoparticles in a single step. Direct synthesis was achieved by radiolysis of an aqueous solutions of $\mathrm{HAuCl}_{4}$ in the Missouri University of Science and Technology reactor. Combining neutron and $\gamma$-irradiation in a nuclear reactor allows simultaneous chemical reduction and neutron activation, reducing production time. Radiation-induced synthesis has two main advantages over conventional methods. First, the nanoparticles are of high purity because of the elimination of process by-products and contamination. Second, particle size and structure can be finely controlled through modification of the dose rate and total dose (24).

\section{MATERIALS AND METHODS}

The chemical gold precursor was $99.99 \%$ (metal basis) gold chloride $\left(\mathrm{HAuCl}_{4} \cdot 3 \mathrm{H}_{2} \mathrm{O}\right.$; American Chemical Society), and the colloidal stabilizer was $99.99 \%$ polyvinylpyrrolidone (molecular weight; 360,000). Both reagents were purchased from Alfa-Aesar. The radical scavenger was 2-propanol, and the medium was deionized water.

A solution of $2 \mathrm{mM} \mathrm{HAuCl} 4,1 \mathrm{mM}$ polyvinylpyrrolidone (molecular weight, 360,000), and $60 \mathrm{mM}$ 2-propanol was prepared using deionized water at room temperature. This composition does not lead to any thermal reduction of the gold salt. Pure nitrogen was bubbled through the solution for $30 \mathrm{~min}$ to remove oxygen and ensure that the reduction process was due to the radiolysis products: hydrated electrons and $\mathrm{H}$ - atoms with negative redox potential. A similar procedure has been previously published (25). The irradiation process was performed in the Missouri University of Science and Technology reactor operating at a thermal power of $200 \mathrm{~kW}$. Seven different 2-mL samples were irradiated for 0.5, 1, 3, 5, 10, 30, or $60 \mathrm{~min}$ each. The nanoparticles in solution were characterized for morphology, size distribution, and chemical composition using a transmission electron microscope (Technai F20) with the help of the Java-based image-processing program ImageJ.

\section{RESULTS}

Chemically stable radioactive gold nanoparticles were successfully produced in a single step from combined $\gamma$ - and neutron irradiation of the precursor solution. As previously shown, nanoparticle synthesis is likely initiated by the radiolytic reduction of water and by species such as hydrated electrons, $\mathrm{H} \cdot, \mathrm{OH}^{-}, \mathrm{H}_{2} \mathrm{O}_{2}$, and $\mathrm{H}_{2}$, which reduce metal ions in the solution (26-30). After the irradiation process, the solution changed color from light yellow to dark red. Samples that were irradiated for shorter times had a lighter color than samples that were irradiated for longer times. As expected, the difference in color change was due to the different sizes of nanoparticles that were produced by the different irradiation durations. Figure 1 shows transmission electron microscope images of the 7 samples, from shorter to longer irradiation times. The average particle sizes and their corresponding SDs are shown in Table 1. The transmission electron microscope images show the presence of gold nanoparticles in all irradiated samples, meaning that it is possible to synthesize nanoparticles even with a small dose. Despite the addition of polyvinylpyrrolidone to the solution, it was not possible to avoid agglomeration of some particles. This agglomeration may have been due to the time that elapsed between irradiation and microscopy, because the samples could not be transported and analyzed until after the activity had decayed. However, most particles remained nonagglomerated.

The variation in average particle size and SD with irradiation time is shown in Figure 2. Following a power trend, both the size and the SD of gold nanoparticles decreased with longer radiation times, with $R^{2}$ values of 0.968 and 0.996 , respectively. After $60 \mathrm{~min}$ of irradiation, a 93\% reduction in particle size was achieved. Most of the reduction occurred during the first $10 \mathrm{~min}$ of irradiation (79\%). Afterward, the average reduction rate dropped to $0.3 \%$ per minute. The same behavior was observed for SD.

The variation in particle size with irradiation time can be explained by a nucleation-and-growth theory. Low absorbed doses create few nucleation points at which the atoms can begin to coalesce, and nanoparticles grow until the metal

TABLE 1

Average Particle Size with Irradiation Time

\begin{tabular}{lcccc}
\hline Sample & $\begin{array}{c}\text { Irradiation } \\
\text { time }(\mathrm{min})\end{array}$ & $\begin{array}{c}\text { Average } \\
\text { size }(\mathrm{nm})\end{array}$ & $\begin{array}{c}\text { SD } \\
(\mathrm{nm})\end{array}$ & $\begin{array}{c}\text { SD } \\
(\%)\end{array}$ \\
\hline 1 & 0.5 & 271 & 207 & 76 \\
2 & 1 & 221 & 126 & 57 \\
3 & 3 & 124 & 75 & 60 \\
4 & 5 & 86 & 47 & 55 \\
5 & 10 & 56 & 34 & 61 \\
6 & 30 & 37 & 16 & 43 \\
7 & 60 & 19 & 8 & 42 \\
\hline
\end{tabular}




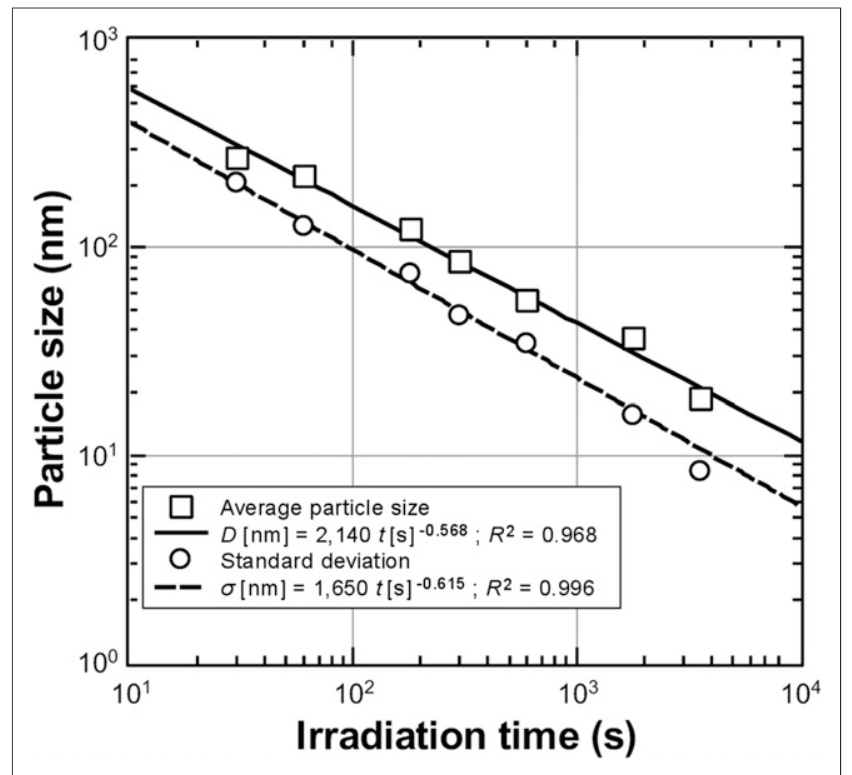

FIGURE 2. Variation of average size and SD with irradiation time.

precursor is consumed. However, higher absorbed doses produce a higher number of nucleation points, resulting in nanoparticles of smaller size. This argument is supported by previous studies $(24,31)$.

The size distribution of gold nanoparticles used in cancer treatment has been found to be a key parameter in improving retention in tumors, interstitial interaction within the body, and an efficient cell-killing process (32-34). Particles between 1 and $100 \mathrm{~nm}$ in diameter are smaller than the pores in typical tumor vasculature, allowing the particles access to tumor cells (34). Meanwhile particles smaller than $10 \mathrm{~nm}$ are efficiently removed from the body through the kidneys. Sensitization and cell uptake were greater for nanoparticles approximately $50 \mathrm{~nm}$ in diameter than for

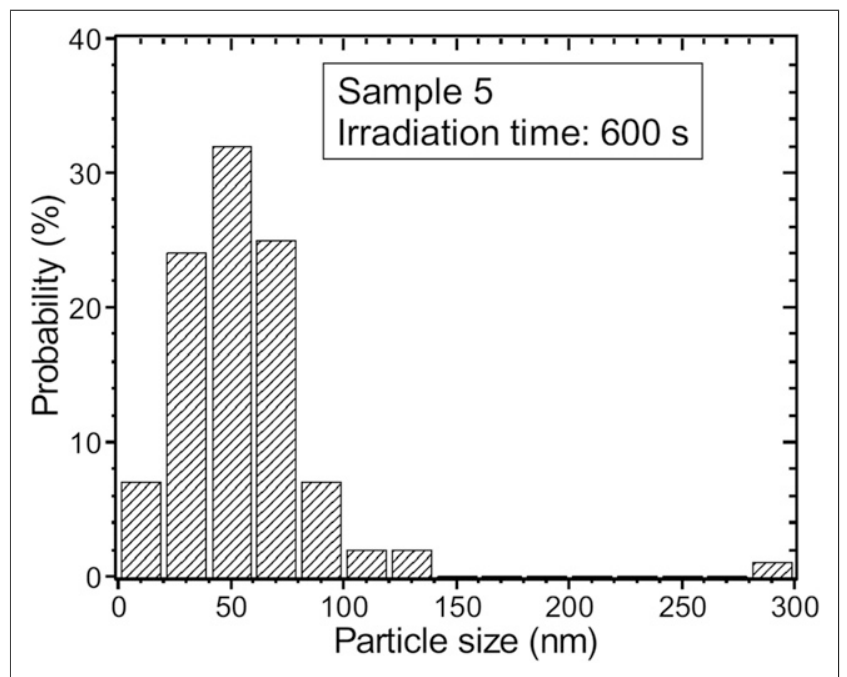

FIGURE 3. Particle population vs. probability for sample 5.
FIGURE 4. Energy-dispersive spectroscopy graph for sample 5 .

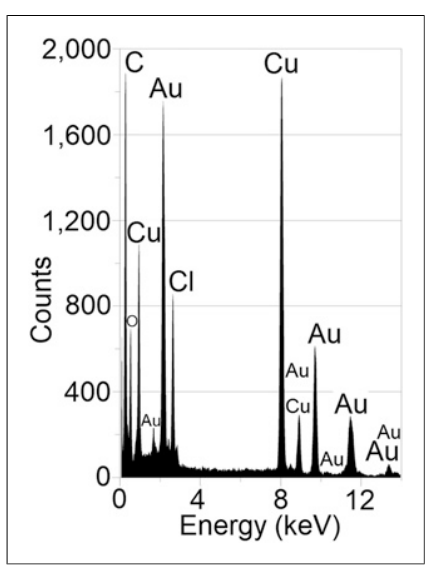

other sizes (35-39). For this reason, 50-nm particles represent the most promising option for cancer treatment. In this study, sample 5 (irradiated for $10 \mathrm{~min}$ ) was populated by gold nanoparticles with the best characteristics for use in cancer treatment, with an obtained average particle size of $56 \mathrm{~nm}$ and an SD of $34 \mathrm{~nm}$. Figure 3, which graphs particle population versus probability for sample 5 , shows that $95 \%$ of the particles fell into the acceptable size range for cancer treatment (10-100 nm) and that $32 \%$ were at the preferred size $(40-60 \mathrm{~nm})$. The largest particle obtained in sample 5 was $296 \mathrm{~nm}$ in diameter; because this particle fell into an isolated size range, it was probably due to particle agglomeration.

Chemical composition was verified using energy-dispersive spectroscopy to determine the possible presence of other chemical species through contamination or by-products. Figure 4 shows the energy dispersive spectroscopy graph for sample 5, and Table 2 shows the composition-in weight percentage and atomic percentage-and the uncertainty for each element found in the spectrum. These analyses were performed for all samples, with the results being $99 \%$ similar to those for sample 5 .

As shown in Table 2, the weight percentage of gold in the sample $(71.7 \%)$ demonstrated effective reduction of gold, as well as production of metallic gold nanoparticles without foreign contamination. The presence of chlorine in the spectrum was expected because of the presence of chloride in the precursor solution. The presence of copper and carbon was due to the sample holder (polyvinyl formal/ carbon on 300-mesh copper) of the transmission electron microscope.

TABLE 2

Weight and Atomic Composition of Elements in the Spectrum

\begin{tabular}{lccc}
\hline Element & Weight (\%) & Atomic (\%) & Uncertainty (\%) \\
\hline Chlorine & 28 & 69 & 3 \\
Gold & 72 & 31 & 10 \\
\hline
\end{tabular}


Finally, the activity of the produced solutions was calculated for thermal, intermediate, and fast neutron populations to estimate their potential suitability for cancer treatment:

$$
A[\mathrm{~Bq}]=\left(\begin{array}{lllll}
M & V & N_{a}
\end{array}\right) \sigma \phi\left(1-e^{\left(\frac{-\ln 2 t}{T_{1} / 2}\right)}\right),
$$

where $M$ is the molarity of the irradiated samples $(0.002 \pm$ $0.0001 \mathrm{M}) ; V$ is the sample volume $(0.002 \pm 0.0001 \mathrm{~L}) ; N_{a}$ is Avogadro's number; $\sigma_{t}, \sigma_{i}$, and $\sigma_{f}$ are, respectively, the thermal neutron capture cross section $\left(98.7 \times 10^{-24} \mathrm{~cm}^{2}\right)$, resonance integral $\left(1,550 \times 10^{-24} \mathrm{~cm}^{2}\right)$, and fast neutron capture cross section $\left(6.22 \times 10^{-24} \mathrm{~cm}^{2}\right)$ for ${ }^{198} \mathrm{Au}$; $\phi$ is the neutron flux of the Missouri University of Science and Technology reactor at full power $\left(2.94 \pm 0.02 \times 10^{12}\right.$, $1.86 \pm 0.04 \times 10^{12}$, and $2.65 \pm 0.03 \times 10^{12} \mathrm{n} / \mathrm{cm}^{2} \cdot \mathrm{s}$, for $\sigma_{t}, \sigma_{i}$, and $\sigma_{f}$, respectively) (40); $t$ is the irradiation time for each sample $( \pm 0.5 \mathrm{~s})$; and $\mathrm{T}_{1 / 2}$ is the half-life for ${ }^{198} \mathrm{Au}$ $(2.695 \mathrm{~d})$. Table 3 shows the total calculated activities (in $\mathrm{MBq} / \mathrm{mL}$ of irradiated solution) of all samples.

In comparison with a previous study (13), samples 6 and 7 reached adequate activity to treat cancer tumors $(>15$ $\mathrm{MBq} / \mathrm{mL}$ ) whereas the other samples reached lower activities $(<10 \mathrm{MBq} / \mathrm{mL})$. However, the nanoparticles obtained from sample 5 showed the appropriate morphology to improve tumor retention and interstitial interaction in tumor vasculature.

\section{DISCUSSION}

Single-step synthesis of radioactive gold nanoparticles was successfully accomplished using a research nuclear reactor. The nanoparticles exhibited physical, chemical, and radioactive characteristics that allow potential use in cancer diagnosis and treatment. The use of a nuclear reactor allowed simultaneous $\gamma$ - and neutron irradiation, producing radioactive nanoparticles and reducing production time. $\mathrm{Fu}-$ ture work will include studies on the effect of different irradiation doses on particle synthesis, nucleation site density, and other nanoparticle characteristics, as well as studies to determine the radiochemical purity of the nanoparticles. In vitro and in vivo studies of these radioactive nanoparticles to

TABLE 3

Calculated Activities for Each Irradiated Sample

\begin{tabular}{lcc}
\hline Time $(\min )$ & Activity $(\mathrm{MBq} / \mathrm{mL})$ & Error $(\%)$ \\
\hline 0.5 & 0.34 & 5.2 \\
1 & 0.69 & 5.0 \\
3 & 2.06 & 5.0 \\
5 & 3.43 & 5.0 \\
10 & 6.85 & 5.0 \\
30 & 20.52 & 5.0 \\
60 & 40.94 & 5.0 \\
\hline
\end{tabular}

identify their suitability and effectiveness as cancer treatments are also needed. Further fine-tuning of the irradiation and precursor parameters of the radioactive nanoparticles is recommended to optimize their morphology.

\section{CONCLUSION}

Direct production of chemically stable radioactive gold nanoparticles was successfully accomplished using the Missouri University of Science and Technology reactor. The nanoparticles had physical and radioactive characteristics potentially useful for cancer treatment and diagnosis.

\section{DISCLOSURE}

This work was partially supported by the NRC under grants NRC-HQ-12-G-38-0075 and PPR-NRC-38-10-966. No other potential conflict of interest relevant to this article was reported.

\section{ACKNOWLEDGMENTS}

We are grateful to William Bonzer and the staff of the Missouri University of Science and Technology reactor for assistance with experimental irradiation. Also, we appreciate the support of the Materials Research Center (MRC) at the Missouri University of Science and Technology.

\section{REFERENCES}

1. Mendis S. Global Status Report on Noncommunicable Diseases 2014. Geneva, Switzerland: World Health Organization; 2014:10.

2. Siegel RL, Miller KD, Jemal A. Cancer statistics, 2017. CA Cancer J Clin. 2017;67:7-30.

3. Satija J, Gupta U, Jain NK. Pharmaceutical and biomedical potential of surface engineered dendrimers. Crit Rev Ther Drug Carrier Syst. 2007; 24:257-306.

4. Stone HB, Coleman CN, Anscher MS, McBride WH. Effects of radiation on normal tissue: consequences and mechanisms. Lancet Oncol. 2003;4:529-536.

5. Bertrand N, Wu J, Xu X, Kamaly N, Farokhzad OC. Cancer nanotechnology: the impact of passive and active targeting in the era of modern cancer biology. $A d v$ Drug Deliv Rev. 2014;66:2-25.

6. Hauck TS, Ghazani AA, Chan WC. Assessing the effect of surface chemistry on gold nanorod uptake, toxicity, and gene expression in mammalian cells. Small. 2008;4:153-159.

7. Connor EE, Mwamuka J, Gole A, Murphy CJ, Wyatt MD. Gold nanoparticles are taken up by human cells but do not cause acute cytotoxicity. Small. 2005;1:325-327.

8. Davis PH, Morrisey CP, Tuley SMV, Bingham CI. Synthesis and stabilization of colloidal gold nanoparticle suspensions for SERS. In: Nanoparticles: Synthesis, Stabilization, Passivation, and Functionalization. Vol. 996. New York, NY: Oxford University Press; 2008:16-30.

9. Chen J, Wang D, Xi J, et al. Immuno gold nanocages with tailored optical properties for targeted photothermal destruction of cancer cells. Nano Lett. 2007; 7:1318-1322.

10. El-Sayed IH, Huang X, El-Sayed MA. Selective laser photo-thermal therapy of epithelial carcinoma using anti-EGFR antibody conjugated gold nanoparticles. Cancer Lett. 2006;239:129-135.

11. Gobin AM, Lee MH, Halas NJ, James WD, Drezek RA, West JL. Near-infrared resonant nanoshells for combined optical imaging and photothermal cancer therapy. Nano Lett. 2007;7:1929-1934.

12. Melancon MP, Lu W, Yang Z, et al. In vitro and in vivo targeting of hollow gold nanoshells directed at epidermal growth factor receptor for photothermal ablation therapy. Mol Cancer Ther. 2008;7:1730-1739.

13. Chanda N, Kan P, Watkinson LD, et al. Radioactive gold nanoparticles in cancer therapy: therapeutic efficacy studies of GA-198 AuNP nanoconstruct in prostate tumor-bearing mice. Nanomedicine. 2010;6:201-209. 
14. Kannan R, Zambre A, Chanda N, et al. Functionalized radioactive gold nanoparticles in tumor therapy. Wiley Interdiscip Rev Nanomed Nanobiotechnol. 2012;4:42-51.

15. Alizadeh M, Qaradaghi V. Simulation of radioactive gold nanoparticles functionalized with gum arabic glycoprotein in liver cancer therapy. Presented at: 41st Annual Northeast Biomedical Engineering Conference (NEBEC); April 17-19, 2015; Troy, New York.

16. Knight PJ, Doornbos JF, Rosen D, Lin JJ, Farha GJ. The use of interstitial radiation therapy in the treatment of persistent, localized, and unresectable cancer in children. Cancer. 1986;57:951-954.

17. Rich TA. Radiation therapy for pancreatic cancer: eleven year experience at the JCRT. Int J Radiat Oncol Biol Phys. 1985;11:759-763.

18. Patyánik M, Mayer Á, Polgár I. Results of ovary tumor treatment with abdominally administered ${ }^{198} \mathrm{Au}$ evaluated on the basis of long term follow up. Pathol Oncol Res. 2002;8:54-57.

19. Kannan R, Rahing V, Cutler C, et al. Nanocompatible chemistry toward fabrication of target-specific gold nanoparticles. J Am Chem Soc. 2006;128: $11342-11343$.

20. Li J, Wu J, Zhang X, et al. Controllable synthesis of stable urchin-like gold nanoparticles using hydroquinone to tune the reactivity of gold chloride. J Phys Chem C. 2011;115:3630-3637.

21. Goulet PJ, Lennox RB. New insights into Brust-Schiffrin metal nanoparticle synthesis. J Am Chem Soc. 2010;132:9582-9584.

22. Nune SK, Chanda N, Shukla R, et al. Green nanotechnology from tea: phytochemicals in tea as building blocks for production of biocompatible gold nanoparticles. J Mater Chem. 2009;19:2912-2920.

23. Kattumuri V, Katti K, Bhaskaran S, et al. Gum arabic as a phytochemical construct for the stabilization of gold nanoparticles: in vivo pharmacokinetics and $\mathrm{x}$ ray-contrast-imaging studies. Small. 2007;3:333-341.

24. Abedini A, Daud AR, Hamid MA, Othman NK, Saion E. A review on radiationinduced nucleation and growth of colloidal metallic nanoparticles. Nanoscale Res Lett. 2013;8:474.

25. Li T, Park HG, Choi SH. $\gamma$-irradiation-induced preparation of Ag and Au nanoparticles and their characterizations. Mater Chem Phys. 2007;105:325-330.

26. Belloni J, Mostafavi M, Remita H, Marignier JL, Delcourt MO. Radiationinduced synthesis of mono-and multi-metallic clusters and nanocolloids. New J Chem. 1998;22:1239-1255.

27. Rojas JV, Castano CH. Synthesis of rhenium oxide nanoparticles (RexOy) by gamma irradiation. Radiat Phys Chem. 2014;99:1-5.
28. Rojas JV, Castano CH. Production of palladium nanoparticles supported on multiwalled carbon nanotubes by gamma irradiation. Radiat Phys Chem. 2012;81:16-21.

29. Rojas JV, Castano CH. Radiolytic synthesis of iridium nanoparticles onto carbon nanotubes. J Nanopart Res. 2014;16:2567.

30. Rojas J, Castano $\mathrm{CH}$. Production and characterization of supported transition metal nano-particles on multi-walled carbon nanotubes functionalized by gamma irradiation and chemical processes. In: TMS 2011 140th Annual Meeting and Exhibition, Materials Processing and Energy Materials. San Diego, CA: John Wiley and Sons; 2011:237-244.

31. Thanh NT, Maclean N, Mahiddine S. Mechanisms of nucleation and growth of nanoparticles in solution. Chem Rev. 2014;114:7610-7630.

32. Butterworth KT, Coulter JA, Jain S, et al. Evaluation of cytotoxicity and radiation enhancement using $1.9 \mathrm{~nm}$ gold particles: potential application for cancer therapy. Nanotechnology. 2010;21:295101.

33. Herold D M, Das IJ, Stobbe CC, Iyer RV, Chapman JD. Gold microspheres: a selective technique for producing biologically effective dose enhancement. Int J Radiat Biol. 2000;76:1357-1364.

34. Chen W, Zhang J. Using nanoparticles to enable simultaneous radiation and photodynamic therapies for cancer treatment. J Nanosci Nanotechnol. 2006;6: 1159-1166.

35. Unezaki S, Maruyama K, Hosoda JI, et al. Direct measurement of the extravasation of polyethyleneglycol-coated liposomes into solid tumor tissue by in vivo fluorescence microscopy. Int J Pharm. 1996;144:11-17.

36. Malugin A, Ghandehari H. Cellular uptake and toxicity of gold nanoparticles in prostate cancer cells: a comparative study of rods and spheres. J Appl Toxicol. 2010;30:212-217.

37. Aoyama Y, Kanamori T, Nakai T, et al. Artificial viruses and their application to gene delivery: size-controlled gene coating with glycocluster nanoparticles. $J \mathrm{Am}$ Chem Soc. 2003;125:3455-3457.

38. Chithrani BD, Ghazani AA, Chan WC. Determining the size and shape dependence of gold nanoparticle uptake into mammalian cells. Nano Lett. 2006;6: $662-668$.

39. Osaki F, Kanamori T, Sando S, Sera T, Aoyama Y. A quantum dot conjugated sugar ball and its cellular uptake: on the size effects of endocytosis in the subviral region. J Am Chem Soc. 2004;126:6520-6521.

40. Kulage ZA, Castano CH, Usman S, Mueller G. Characterization of the neutron flux energy spectrum at the Missouri University of Science and Technology Research Reactor (MSTR). Nucl Eng Des. 2013;261:174180. 